\title{
Erratum to: Patellar Tracking and Anterior Knee Pain are Similar After Medial Parapatellar and Midvastus Approaches in Minimally Invasive TKA
}

Boonchana Pongcharoen MD, Thanasak Yakampor MD, Keerati Charoencholvanish MD

Published online: 5 November 2014

(C) The Association of Bone and Joint Surgeons ® 2014

Erratum to: Clin Orthop Relat Res (2013) 471:1654-1660 DOI 10.1007/s11999-012-2778-5

In the published study, "Patellar Tracking and Anterior Knee Pain are Similar After Medial Parapatellar and
Midvastus Approaches in Minimally Invasive TKA" the first author's name is spelled incorrectly. The first author's name is Boonchana Pongcharoen MD.

The authors regret the error.

The online version of the original article can be found under doi:10.1007/s11999-012-2778-5.

B. Pongcharoen $(\varangle)$, T. Yakampor

Department of Orthopaedic Surgery, Faculty of Medicine,

Thammasat University Thailand, 95 moo8 Klong, Klongluang,

Patumthani 12120, Thailand

e-mail: boonbigbear@hotmail.com

K. Charoencholvanish

Department of Orthopaedic Surgery, Faculty of Medicine,

Siriraj Hospital, Mahidol University, Bangkok, Thailand 